\title{
Mucosal tears during colonoscopy in a patient with ulcerative colitis
}

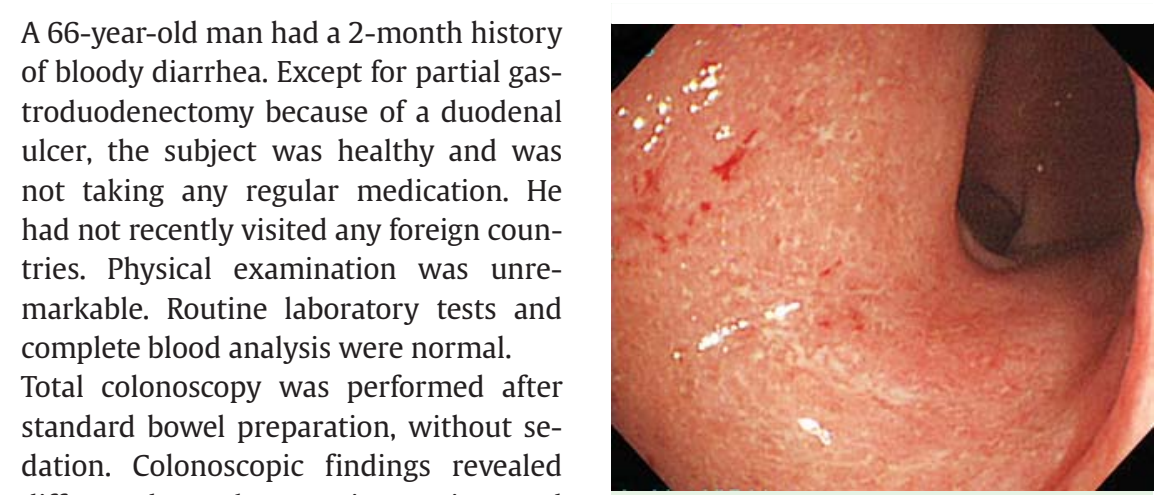

diffuse edema, hyperemia, erosion, and granular mucosa from the rectum to the cecum ( $\bullet$ Fig. 1).

On withdrawal of the endoscope longitudinal mucosal tears were noted in the transverse colon ( Fig. 2 ), whereas such mucosal tears were not observed during the insertion of the endoscope.

Histopathological examination of samples taken from the cecum to the rectum showed moderate to severe mucosal inflammation with cryptitis, crypt destruction, and goblet cell depletion, without subepithelial deposition of a collagen band, which was consistent with the histological finding of ulcerative colitis (๑ Fig. 3).

Richieri et al. reported the unique clinical presentation of longitudinal mucosal tears for the first time in a patient with collagenous colitis [1]. Endoscopic examination usually reveals normal colonic mucosa, although minimal mucosal edema and hyperemia may be present; however, mucosal tears or fracture are characteristic of collagenous colitis [2].

To date, mucosal tears have not been reported in patients with ulcerative colitis, except for a case report of mucosal tears occurring on remnant rectal mucosa on endoscopic insufflation in a patient with ulcerative colitis [3]. Mucosal tears have not been reported in the colonic mucosa of patients with ulcerative colitis, therefore mucosal inflammation alone is not sufficient to explain the cause of mucosal tears in the colonic mucosa. Owing to the possible occurrence of mucosal tears that will lead to colonic perforation, careful colonoscopic examination is required, even in the case of ulcerative colitis patients with mildly active mucosa.

Endoscopy_UCTN_Code_CPL_1AJ_2AB

Fig. 1 Colonoscopic findings of diffuse edema, hyperemia, erosion, and granular mucosa from the rectum to the cecum.

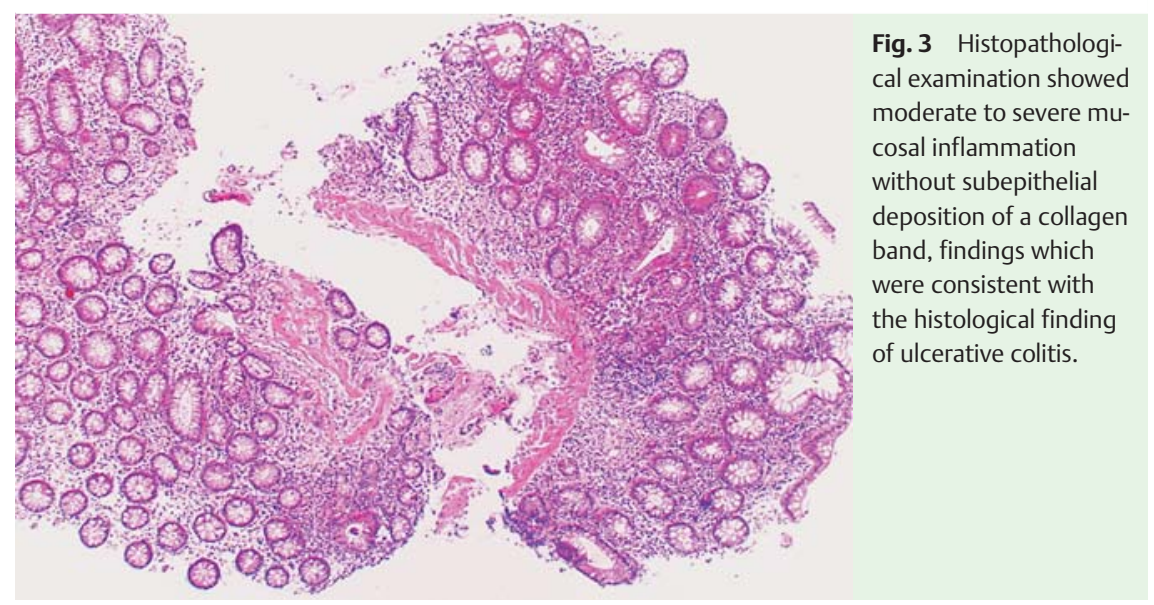

Competing interests: None

\section{N. Oshitani ${ }^{1}$, K. Aomatsu ${ }^{1}$,}

H. Yamagami ${ }^{2}$, R. Ogawa ${ }^{3}$

1 Department of Gastroenterology, Izumiotsu Municipal Hospital, Osaka, Japan

2 Department of Gastroenterology, Osaka City University Graduate School of Medicine, Osaka, Japan

3 Medical Care and Medical Center, Osaka Medical Association, Osaka, Japan

\section{References}

1 Richieri J-P, Bonneau H-P, Cano $N$ et al. Collagenous colitis: an unusual endoscopic appearance. Gastrointestinal Endosc 1993; 39: $192-194$

2 Allende DS, Taylor SL, Bronner MP. Colonc perforation as a complication of collagenous colitis in a series of 12 patietns. Am J Gastroenterol 2008; 103: 2598-2604

3 Hata K, Watanabe T, Kanazawa T et al. Mucosal tears on endoscopic insufflation. Gut 2003; 52: 613

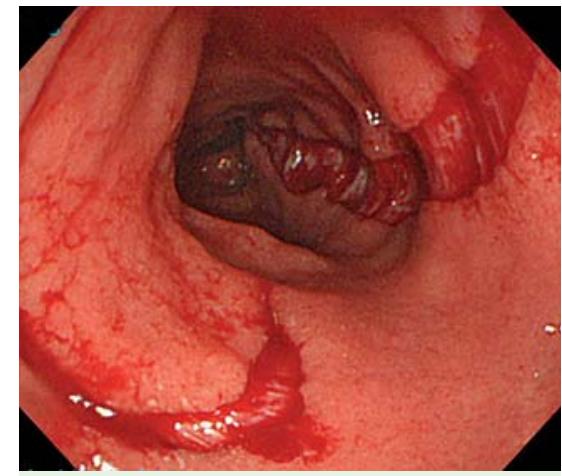

Fig. 2 Longitudinal mucosal tears were noted in the transverse colon during withdrawal of the endoscope.
Nobuhide Oshitani

Department of Gastroenterology

Izumiotsu Municipal Hospital

16-1, Shimojuou-machi

Izumiootu City

Osaka 595-3027

Japan

endoscope@hosp-ozu-osaka.jp 